\title{
Antibacterial Activity of Marine Bacillus Substances against Vibrio cholerae and Staphylococcus aureus and In Vivo Evaluation Using Embryonic Zebrafish Test System
}

\author{
C. RAVINDRAN*, G. R.VARATHARAJAN, R. RAJASABAPATHY AND R. A. SREEPADA \\ Biological Oceanography Division, Biotechnology lab, CSIR-National Institute of Oceanography, Dona Paula, \\ Goa-403 004, India
}

\section{Ravindran, et al.: Antibacterial Activity of Marine Bacillus against Infectious Agents}

\begin{abstract}
Cell free extracts of Bacillus subtilis subsp. spizizenii and B. thuringiensis isolated from hydrothermal vent region of Azorean Island Faial, North Atlantic Ocean showed antagonistic against Vibrio cholera serogroup 01 and Staphylococcus aureus, respectively. The in vitro inhibition of infectious pathogens by both $B$. subtilis subsp. spizizenii and $B$. thuringiensis was concentration dependent. The result of sensitivity to protease test showed considerable reduction of antibacterial activity for both Bacillus strains, indicating the proteinaceous nature of the antibacterial substances. Further, our results on antibacterial substance of heat-resistant, proteinaceous nature and bacteriostatic mode of action was evaluated for the toxicity studies using zebrafish animal model, an alternative to the use of antibiotics test against infectious diseases. Bacillus antibacterial extracts showed no toxic effects with the Staphylococcus aureus-zebra fish embryo infection studies.
\end{abstract}

Key words: Antagonistic, bacterial disease, marine bacteria, Pathogen, zebrafish

The production of antimicrobial substances by marine bacteria isolated from different locations in the sea has been known for long time ${ }^{[1,2]}$. But the usage of marine bacteria obtained from hydrothermal vent regions as a potential antibacterial agent against pathogenic disease was not much studied. In our earlier study we had reported several bacterial strains isolated from hydrothermal vent regions of Dom João de Castro Seamount (DJCS) located in the North Atlantic ocean, between the Azorean Islands of São Miguel and Terceira $\left(38^{\circ} 13.3^{\prime} \mathrm{N}, 26^{\circ} 36.2^{\prime} \mathrm{W}\right)$, lies on the Terceira Rift ${ }^{[3]}$ and a new shallow hydrothermal vent field discovered in 2010 at a depth of $30 \mathrm{~m}$, which is located close to the Faial Island, just outside the Espalamaca (38 $33^{\prime} \mathrm{N}$; $\left.28^{\circ} 39^{\prime} \mathrm{W}\right)^{[4]}$. We admitted some of the Bacillus strains from this collection for screening potential antimicrobial activity against pathogenic Vibrio and Staphylococcus sp.

So far conventional approaches such as use of antimicrobial drugs to control diseases have had success in the prevention or cure of disease caused by Vibrio, Staphylococcus sp. and other pathogens. The massive use of antibiotics encourages natural emergence of antibiotic resistant bacteria, which can transfer their resistance genes to other bacteria that have never been exposed to the antibiotics. Furthermore, most of the antibiotics have been reported for the side effects for the consumers. Hence, the use of beneficial bacteria (probiotics) to displace pathogenic bacteria by competitive processes was considered as a better remedy than administering antibiotics. Bacillus species are used in many medical, pharmaceutical, agricultural, and other industrial processes for their ability to produce a host of enzymes, antibiotics, and other metabolites. Bacillus strains have also been utilized as biological controls in antibiotics and other assays. Further, several in vivo experimental model approaches have been used to understand the bacterial infections and drug toxicity analysis. The drug evaluation with several other mammalian models is found to be costly and slow, but zebrafish are considered for a rapid

This is an open access article distributed under terms of the Creative Commons Attribution-NonCommercial-ShareAlike 3.0 License, which allows other the remix, tweak, and build up to the non-commercially, as long as the author is credited and the new creations are licensed under the identical terms.

Accepted 09 Jun 2016

Revised 02 Jun 2016

Received 26 Sep 2015

Indian J Pharm Sci 2016;78(3):417-422 
and high throughput analysis, which has an immune system similar to that of humans and other vertebrates including fishes. Thus, our present investigation includes, identification of potential Bacillus species from marine source for its ability to act as a biocontrol agent against bacterial pathogens using zebrafish as a test system.

Five selected Bacillus strains isolated from hydrothermal vent regions were used in this study for their antibacterial activity. Vibrio cholera serogroup 01 (MTCC 3904) (obtained from Microbial Type Culture Collection, IMTECH, Chandigarh, India), $V$. parahaemolyticus, $V$. harveyi, $V$. alginolyticus (isolated from fish gut, and identified using biochemical test and species specific media) and Staphylococcus sp. (isolated from gut of fish, grey mullet) identified using 16S rRNA sequencing by our earlier methods ${ }^{[5]}$ (obtained GenBank accession number KM029979) and $S$. aureus (obtained from Goa Medical College Hospital, Goa) strains were used for pathogens.

The screening of antagonistic activity assay was made using gram positive Bacillus species obtained from hydrothermal vent region against pathogens by disc diffusion method. Gram negative bacteria, Vibrio pathogens and Staphylococcus sp. were cultured in Zobell marine broth (ZMB) (HiMedia, Mumbai, India) and incubated at $28^{\circ}$ for $24 \mathrm{~h}$ and $100 \mu \mathrm{l}$ of the culture was spread over the tryptic soy agar (TSA) plates. And also TSA medium was cooled and $25 \mu \mathrm{l}$ of pathogens were added, mixed and poured in a sterile petriplates. The disc was prepared from sterilized/autoclaved Whatman no. 1 filter paper $(5 \mathrm{~mm})$. The $5 \mathrm{~mm}$ sterilized discs were placed on the cultured spread plate. Fresh culture of gram positive bacteria $B$. subtilis subsp. spizizenii and $B$. thuringiensis were centrifuged at 12 $000 \mathrm{rpm}$ for $10 \mathrm{~min}$ and the supernatant was filtered through $0.22 \mu \mathrm{m}$ membrane filter (Millipore) for the sterile cell free extracts. Different concentrations (20, 30,40 and $50 \mu 1$ ) of cell free extracts of gram positive bacteria was added into the disc of the Mueller-Hinton agar (MHA) (HiMedia, Mumbai, India) plates and incubated at $30^{\circ}$ for 24 to $48 \mathrm{~h}$. The antimicrobial activity of the isolate was said positive on any appearance of distinct inhibition zone against the pathogenic, species. Thermal stability was determined by heating a $2 \mathrm{ml}$ cell-free supernatant fluid at $50^{\circ}, 75^{\circ}$ and $100^{\circ}$ during 60 and $120 \mathrm{~min}$.

The samples were then assayed for remaining activity by the well diffusion method. In order to test sensitivity to proteases, the supernatant fluid was treated with trypsin (Sigma) and proteinase K (Sigma) at a final concentration of $0.5 \mathrm{mg} / \mathrm{ml}$. The effect of antibacterial compound on sensitive cells was tested by adding 2.5 $\mathrm{ml}$ of concentrated culture supernatants of $B$. subtilis subsp. spizizenii (VSD 609) and B. thuringiensis (VSD 550 ) to $25 \mathrm{ml}$ of a log phase culture of $V$. cholerae 01 and Staphylococcus sp. in nutrient broth. The number of viable cells determined at appropriate intervals by measuring optical density at $600 \mathrm{~nm}\left(\mathrm{OD}_{600}\right)$ with a spectrophotometer. Ciprofloxacin/vancomycin and lysogeny broth (LB) were used as positive and negative control, respectively.

Adult zebrafish of both sexes were brought from a fish farm, Chennai, Tamil Nadu and maintained in tanks containing standard fresh water system under $14 \mathrm{~h} / 10$ $\mathrm{h}$ light-dark photo period. Fish were fed with fish food flakes thrice a day and the temperature approximately at $28^{\circ}$. One male and one female zebrafish were transferred to a breeding tank and separated overnight. Breeding was allowed in the next morning and the sufficient eggs were collected from the breeding tanks. The eggs were washed to remove the unfertilized eggs and debris.

Embryos were selected at the 1-cell stage and exposed $10^{3}, 10^{4}, 10^{5}, 10^{6}$ and $10^{7} \mathrm{CFU} / \mathrm{ml}$ of bacterial pathogens in the petriplates and 6 well plates. All dechorionated embryos were observed after $24 \mathrm{~h}$ of incubation at $30^{\circ}$ to monitor infection, lethality and treatment under a stereomicroscope (Olympus SZ-40, Japan) at different stages from 4 to $120 \mathrm{hpf}$ and photographed for morphological analyses. The bacterial extracts wasted at different dilutions of the MIC along with bacterial pathogens for their inhibitory effect in parallel to the treatment of ciprofloxacin and vancomycin in $1 \%$ dimethyl sulphoxide (DMSO) as vehicle.

V. cholerae infection experiments using zebrafish larvae was performed as described earlier ${ }^{[6]}$. Briefly, 5 day post-fertilization zebrafish larvae were placed into $1 \mathrm{ml}$ tank water containing $1 \times 10^{6} \mathrm{CFU} / \mathrm{ml}$ of $V$. cholerae in a 12 -well plate and incubated for 2 to $24 \mathrm{~h}$ at $27^{\circ}$. At the designated time points, larvae were removed from the well with the bacteria and washed in sterile tank water twice and then placed into a well with a euthanizing dose of clove oil solution. $S$. aureus infections were made by treatment of $1 \times 10^{5} \mathrm{cfu} / \mathrm{ml}$ of inoculum to the dechorionated $2 \mathrm{dpf}$ (days post fertilization) embryos in 6 well plates incubated for $24 \mathrm{~h}^{[7]}$.

Among the five isolates of Bacillus species obtained 
from hydrothermal vent region, B. subtilis subsp. spizizenii (VSD 609) and B. thuringiensis (VSD 550) showed antagonistic activity against $V$. cholera and Staphylococcus sp., respectively (fig. 1A and 1B). The level of inhibitory zone of $B$. subtillis against $V$. cholerae and B. thuringiensis against Staphylococcus sp. was consistent and distinct. The diameter of the inhibitory zone around the $V$. cholerae was about $10-15 \mathrm{~mm}$ and the zone for Staphylococcus sp. was $14-15 \mathrm{~mm}$. The cell free extracts of both the B. subtilis subsp. spizizenii and $B$. thuringiensis gave better zone inhibition with the concentrated supernatants when compared with that of the other live culture and diluted filtrates. Thus, the difference in the zone effect varied depending upon the concentration used (fig. 1A and 1B). The inhibitory activity was not reduced during 60 and 120 min heat
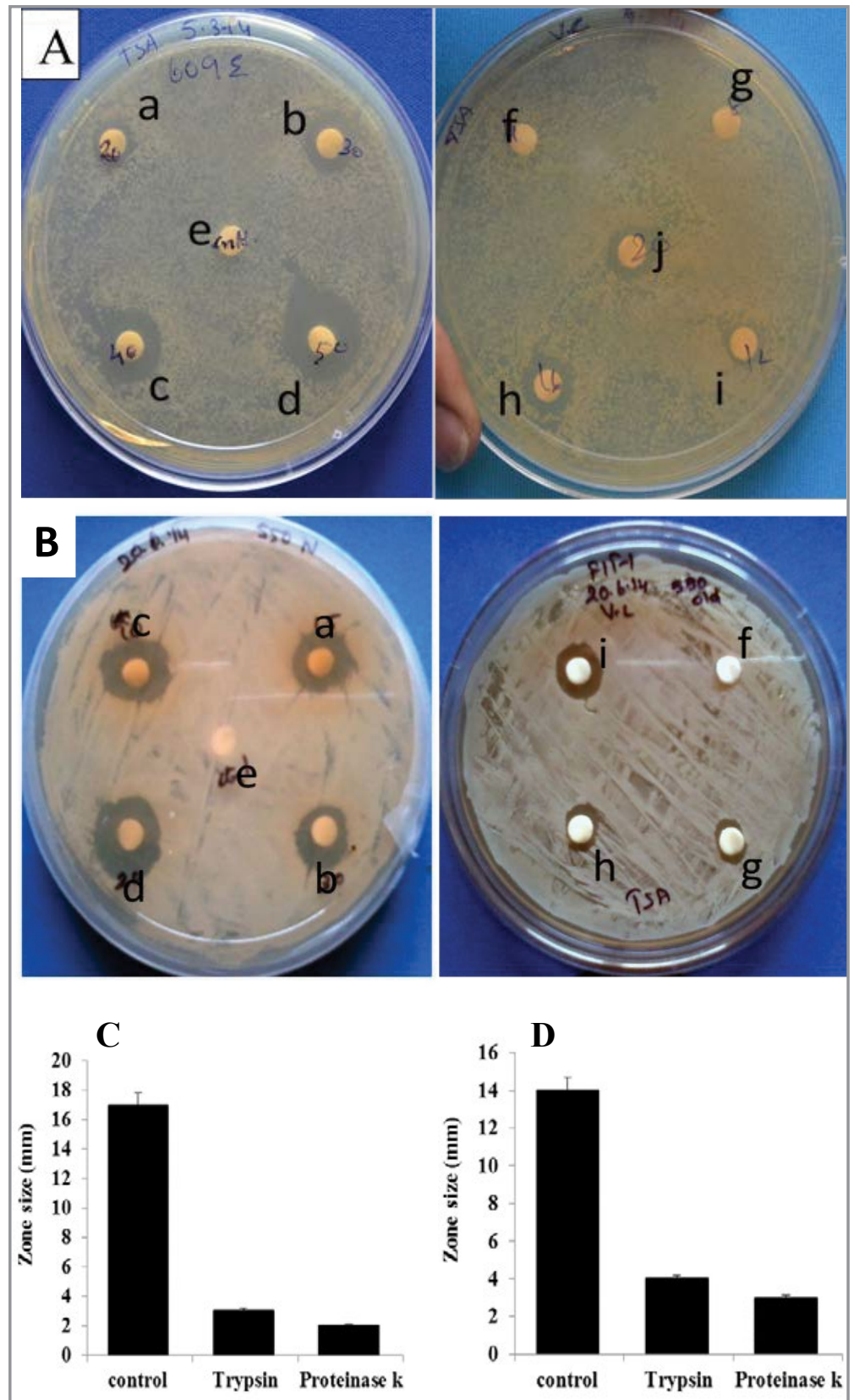

Fig. 1: Analysis of the marine Bacillus cell free extracts against $V$. cholerae and $S$. aureus.

Inhibition of the cell free extracts of strain VSD 609, B. subtilis subsp. spizizenii against $V$. cholerae (A) and VSD 550, B. thuringiensis against $S$. aureus. (B) by the disc diffusion assay. In $\mathrm{A}, \mathrm{a}, \mathrm{b}, \mathrm{c}, \mathrm{d}$ and e disc containing the non-treated cell free extracts with concentrations of $20,30,40,50 \mu l$ and negative control (with only media) respectively. Af, negative control, $\mathrm{Ag}, \mathrm{Ah}, \mathrm{Ai}$ and $\mathrm{Aj}$ with the addition of trypsin $(\mathrm{g}, \mathrm{h})$ and proteinase $k(\mathrm{i}, \mathrm{j})$ when the antagonistic activity was completely and partially destroyed. In $B, a, b, c, d$ and e disc containing the non-treated cell free supernatants with concentration of $20 \mu \mathrm{l}, 30 \mu \mathrm{l}, 40 \mu \mathrm{l}, 50 \mu \mathrm{l}$ and negative control (with only media) respectively. $\mathrm{Bf}, \mathrm{Bg}, \mathrm{Bh}$ and $\mathrm{Bi}$ with the addition of trypsin (f, g) and proteinase $\mathrm{k}(\mathrm{h}, \mathrm{i}) \mathrm{when}$ the antagonistic activity was completely and partially destroyed. Zone measurements of $B$. subtilis extracts against $V$. cholerae (C) and B. thuringiensis against $S$. aureus (D). 
treatment at $100^{\circ}$ showed that both the supernatants of Bacillus sp. are heat resistant. Furthermore, the antagonistic activity showed by the supernatant fluid of both the Bacillus sp. was completely or partially destroyed by the trypsin and proteinase $\mathrm{k}(0.5 \mathrm{mg} / \mathrm{ml}$, fig. 1a-e, f, g, h, i and $1 b-e, f, g, h)$ treatment inferring that antibacterial substance was proteinaceous in nature. The spectrophotometer test on the effect of antibacterial compound of both the B. subtilis subsp. spizizenii and $B$. thuringiensis strains on the sensitive cells showed a stable activity in controlling the pathogens, $V$. cholerae and Staphylococcus sp., ranging from 0.5 to $0.8 \mathrm{OD}$ after $24 \mathrm{~h}$ (fig. 2). The negative control in both the case showed increased population. However, bacterial pathogens treated with ciprofloxin and vancomycin as positive controls showed significant decreased population. These results showed that the antibacterial compound exhibited the bacteriostatic mode of action.

In the present study, B. subtilis subsp. spizizenii showed distinct biocontrol activity against $V$. cholerae serogroup 01. B. subtilis is already described as an antimicrobial peptide (AMP) producer, including a diversity of lipopeptides like iturins (bacillomycins), polymyxins, fengycins (plipastatins), kurstakins ${ }^{[8]}$, and a number of bacteriocins ${ }^{[9]}$. B. subtilis subsp. spizizenii also known for producing antibacterial compounds, like subtilosin A and subtilin ${ }^{[10]}$. Similarly, B. thuringiensis are reported for a number of bacteriocins ${ }^{[11]}$ but only four bacteriocins have been partially characterized ${ }^{[12]}$. Our results on antibacterial substance of heat resistant, proteinaceous nature and bacteriostatic mode of action are congruent with that of other reports ${ }^{[13,14]}$ and suggest that the antibacterial substances of the bacillus species may be of bateriocin related.

$V$. cholerae infections was made in dechorionated 2 dpf (days post-fertilization) zebrafish embryos and reisolated by placing the intestine of the larvae in the X-Gal added plates, as $V$. cholerae will form blue colonies but the other intestinal bacteria will not form blue colonies ${ }^{[6,15]}$. The results showed that the $V$. cholerae infected larvae with more colonies when compare with that of the uninfected. Our results of $V$. cholerae infection in zebra fish larvae was found similar with that of the earlier study ${ }^{[6]}$. The only $V$. cholerae infected embryos showed high mortality than the antibacterial treatment. The latter was treated with bacterial extracts after one hour of $V$. cholerae infection. Furthermore, the treatment of embryos with only B. subtilis antibacterial extracts showed no or very less $V$. cholerae colonies similar to that of the uninfected without any zebra fish larvae mortalities. Thus, our study confirms that the $B$. subtilis antibacterial extracts are safer to use as a drug.

Dechorionated embryos of $2 \mathrm{dpf}$ were treated with $S$. aureus and infections were found after $24 \mathrm{~h}$ incubation. In order to recover bacteria from host tissues, whole zebra fish embryos were individually homogenized in a suitable volume of phosphate-buffered saline (PBS). Homogenates were serially diluted in PBS and plated on nutrient agar to determine bacterial numbers. The infected embryos were found with muscle deformities especially in trunk region and some regions like yolk sac (fig. 3). Treatment of $B$. thuringiensis substances to the infected embryos were found survived with less muscle deformities. The only $B$. thuringiensis substances treated embryos did not showed any deformities such

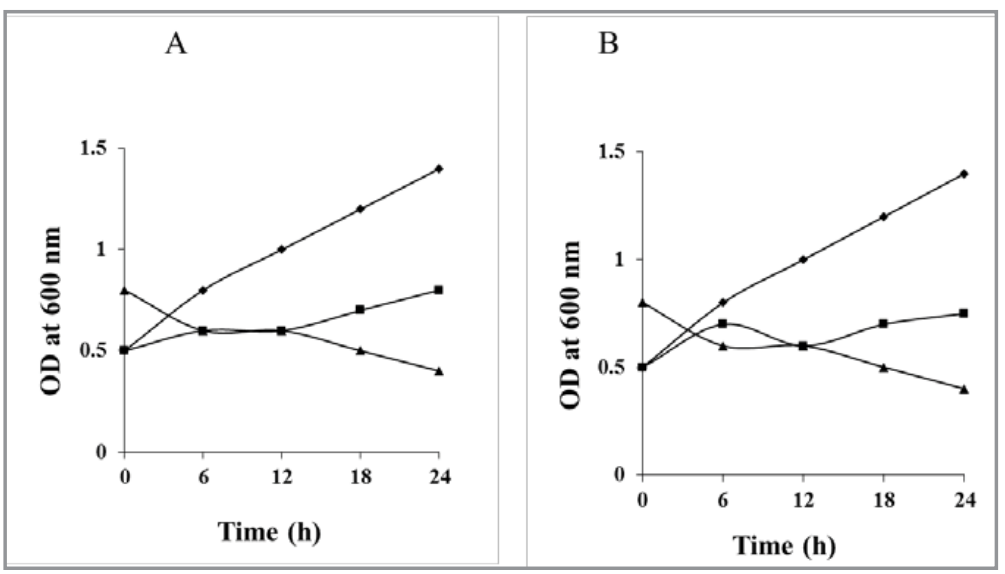

Fig. 2: Evaluation of Bacillus cell free extracts against the pathogens.

The inhibitory activity of inhibition of the cell free extracts of strain VSD 609, B. subtilis subsp. spizizenii (A) (•-Con -ve; $\Delta$-BS; Con +ve) and VSD 550 B. thuringiensis (B) (•-Con-ve; $\Delta-B t$; - Con +ve.) at the optimal condition against V. cholera, Staphylococcus sp. Con +ve presents as positive control (addition of antibiotic ciprofloxin/vancomycin in the broth culture), Con -ve presents as negative control (no addition of antibacterial in the broth culture). Values are means $\pm S D(n=3)$. 


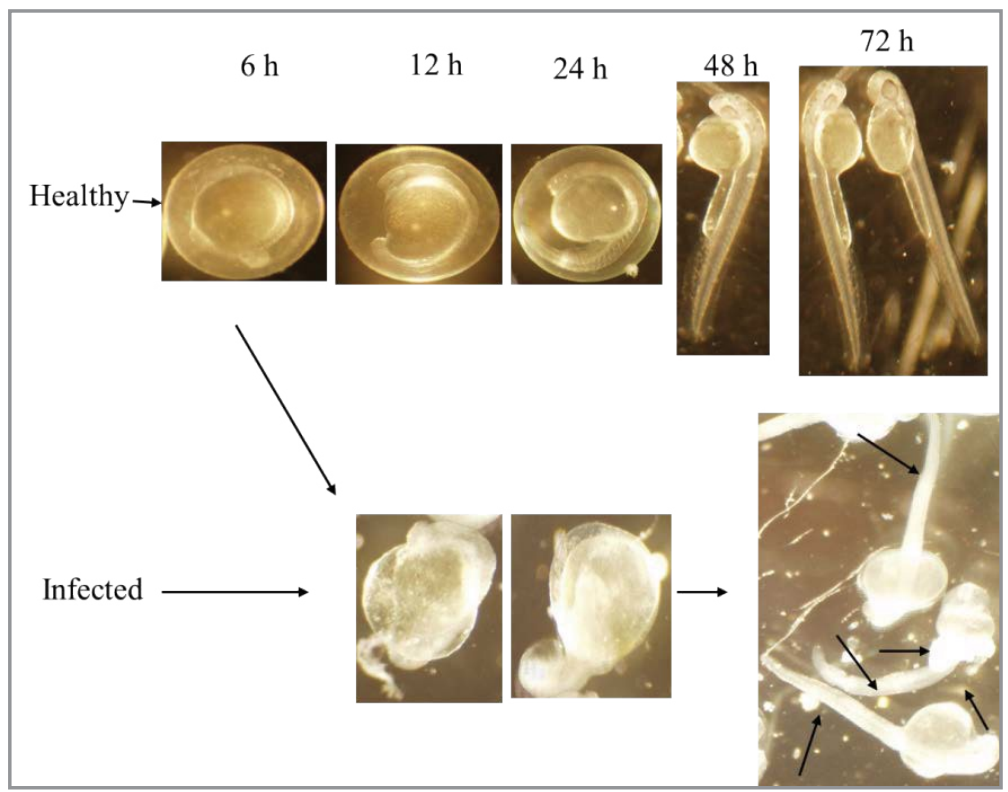

Fig. 3: Infection and treatment studies using zebra fish test system.

The toxicity and infection test was performed in the embryos. The embryos that were treated with only Bacillus antibacterial substances are found healthy as that of the untreated healthy embryos without any toxicity effects like muscle and other growth deformities. $S$. aureus infected embryos showed growth deformities such as muscle loss in trunk, yolk sac.

that of the vancomycin treated embryos. Thus, Bacillus species extracts which are found nontoxic with that of zebra fish may be tested with that of the rat models for further pathophysiological characterization against the above pathogens. Results of antibacterial substance of $B$. thuringiensis against $S$. aureus may be of bacteriocin related protein because of an earlier report stating that Gram-positive strains of bacteriocins are mostly inhibitory to Gram-positive strains ${ }^{[14]}$.

In conclusion, we elucidate the use of zebrafish, a promising model for preclinical drug assessment and toxicity assays against human pathogens. Further, the novel antibacterial substance from Bacillus species showed potent antibacterial activity against human pathogens without any toxicity to the host cells. Further, the antagonistic effect of the hydrothermal vent isolated Bacillus species may further characterized and analyzed using the rat models. This may provide valuable information for the novel drugs for therapeutic applications in controlling the infectious disease.

\section{Financial support and sponsorship:}

Nil.

\section{Conflicts of interest:}

There are no conflicts of interest.

\section{REFERENCES}

1. Chellaram C, Edward JKP. Improved recoverability of bacterial strains from soft coral, Lobophytum sp. for antagonistic activity. J Pure Appl Microbio. 2009;3:649-54.

2. Rosenfeld WD, Zobell CE. Antibiotic production by the marine microorganisms. J Bacteriol.1947;54:393-8.

3. Mohandass C, Rajasabapathy R, Ravindran C, Colaco A, Santos RS, Meena RM. Bacterial diversity and their adaptations in the shallow water hydrothermal vent at D. João de Ca-stro Seamount (DJCS), Azores, Portugal. Cah Biol Mar 2012;53:65-76.

4. Rajasabapathy R, Mohandass C, Colaco A, Dastager SG, Santos RS, Meena RM. Culturable bacterial phylogeny from a shallow water hydrothermal vent of Espalamaca (Faial, Azores) reveals a variety of novel taxa. Curr Sci 2014;106:58-69.

5. Ravindran C, Varatharajan GR. Rajasabapathy R. Vasudevan L. Sreepada RA. Infection and pathogenecity of Myroides odoratimimus (NIOCR-12) isolated from the gut of grey mullet (Mugil cephalus (Linnaeus, 1758)). Microb Pathogenesis 2015;88:22-8.

6. Runft DL, Mitchell KC, Abuaita BH, Allen JP, Bajer S, Ginsburg $\mathrm{K}$, et al. Zebrafish as a natural host model for Vibrio cholerae colonization and transmission. Appl Environ Microbiol. 2014;80:1710-7.

7. Kannan RR, Iniyan AM, Vincent SGP. Production of a compound against methicillin resistant Staphylococcus aureus (MRSA) from Streptomyces rubrolavendulae ICN3 $\&$ its evaluation in zebrafish embryos. Indian $\mathrm{J}$ Med Res 2014;139:913-20.

8. Stein T. Bacillus subtilis antibiotics: structures, syntheses and specific functions. Mol Microbiol 2005;56:845-57.

9. Abriouel H, Franz CMAP, Omar NB, Galvez A. Diversity and applications of Bacillus bacteriocins. FEMS Microbiol Rev 2011;35:201-32.

10. Heinzmann S, Entian KD, Stein T. Engineering Bacillus subtilis ATCC 6633 for improved production of the lantibiotic subtilin. Appl Microbiol Biotechnol 2006;69:532-6. 
11. De la Fuente-Salcido NM, Casados-Vázquez LE, BarbozaCorona JE. Bacteriocins of Bacillus thuringiensis can expand the potential of this bacterium to other areas rather than limit its use only as microbial insecticide. Can $\mathrm{J}$ microbial 2013;59:515-22.

12. Cherif A, Ouzari H, Daffonchio D, Cherif H, Ben Slama K, Hassen A, et al. Thuricin 7: a novel bacteriocin produced by Bacillus thuringiensis BMG1.7, a new strain isolated from soil. Lett Appl Microbiol 2001;32:243-7.

13. Zokaeifar H, Luis Balcazar J, Kamarudin MS, Sijam
K, Arshad A, Saad CR. Selection and identification of nonpathogenic bacteria isolated from fermented pickles with antagonistic properties against two shrimp pathogens. J Antibiot 2012;65:289-94.

14. Gray EJ, Lee KD, Souleimanov AM, Di Falco MR, Zhou $\mathrm{X}$, Ly A, et al. A novel bacteriocin, thuricin 17, produced by PGPR strain Bacillus thuringiensis NEB17: Isolation and classification. J Appl Microbiol 2007;100:545-54.

15. Senderovich Y, Izhaki I, Halpern M. Fish as reservoirs and vectors of Vibrio cholerae. PLoS One 2010;5:e8607. 